\title{
SAperl: Approaching gender gap using Spatial Ability training week in high-school context
}

\author{
Maria Giulia Ballatore \\ Politecnico di Torino \\ Gavin Duffy \\ Technological University Dublin, gavin.duffy@tudublin.ie \\ Sheryl Sorby \\ University of Cincinnati
}

See next page for additional authors

Follow this and additional works at: https://arrow.tudublin.ie/ittengart

Part of the Electrical and Electronics Commons, Engineering Education Commons, and the Mathematics Commons

\section{Recommended Citation}

Ballatore, Maria Giulia; Duffy, Gavin; Sorby, Sheryl; and Tabacco, Anita, "SAperl: Approaching gender gap using Spatial Ability training week in high-school context" (2020). Articles. 6.

https://arrow.tudublin.ie/ittengart/6

This Conference Paper is brought to you for free and open access by the School of Engineering at ARROW@TU Dublin. It has been accepted for inclusion in Articles by an authorized administrator of ARROW@TU Dublin. For more information, please contact arrow.admin@tudublin.ie, aisling.coyne@tudublin.ie, gerard.connolly@tudublin.ie.

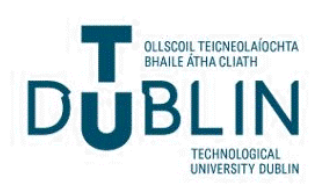


Authors

Maria Giulia Ballatore, Gavin Duffy, Sheryl Sorby, and Anita Tabacco

This conference paper is available at ARROW@TU Dublin: https://arrow.tudublin.ie/ittengart/6 


\section{SAperl: approaching gender gap using Spatial Ability training week in high-school context}

\author{
Maria Giulia Ballatore \\ Dept. of Mathematical Sciences 'G.L. Lagrange', \\ Politecnico di Torino, Torino, Italy \\ maria.ballatore@polito.it
}

\author{
Sheryl Sorby \\ Engineering Education, University of Cincinnati, Ohio, \\ USA \\ sheryl@mtu.edu
}

\author{
Gavin Duffy \\ School of Electrical and Electronic Engineering, \\ Technological University Dublin, Central Quad, \\ Grangegorman Lower, Dublin \\ gavin.duffy@TUDublin.ie \\ Anita Tabacco \\ Dept. of Mathematical Sciences 'G.L. Lagrange', \\ Politecnico di Torino, Torino, Italy \\ anita.tabacco@polito.it
}

\begin{abstract}
The purpose of this paper is to describe the structure of a girls summer school, "SAperI - Spatial Ability per l'Ingegneria" (in English, "Knowledge - Spatial Ability for Engineering"), and to illustrate its impact on spatial ability development and future career preferences on those who participated in the week long summer school compared to a control group that did not participate.The 5 days school, organized by Politecnico di Torino (Italy), was included in a larger project addressing 17 years old high-school students. Thirtyseven girls actively took part in a summer school, while 167 students (both males and females) were tested as a controlled group.For those who attended the summer school, significant gains were observed in four measures of spatial ability - mental rotation, spatial visualization, mental cutting and paper folding. For a minority of participants, scores on one of these tests, paper folding, were lower when measured at the end of the summer school but this was an exception. Furthermore, when tested several months after the summer school, the gains in spatial ability that were made during the course were maintained indicating stability over time with regard to the improvement in spatial ability.In terms of the experience of taking the course, the feedback provided was very positive and all but one participant would recommend the summer school to other girls at this stage of high school.
\end{abstract}

\section{CCS CONCEPTS}

- Social and professional topics; • Gender; • General and reference; • General; • Conference proceedings Information systems; $\bullet$ data management systems;

\section{KEYWORDS}

Spatial Ability, Gender gap, STEM education, High-School student

Permission to make digital or hard copies of all or part of this work for personal or classroom use is granted without fee provided that copies are not made or distributed for profit or commercial advantage and that copies bear this notice and the full citation on the first page. Copyrights for components of this work owned by others than ACM must be honored. Abstracting with credit is permitted. To copy otherwise, or republish, to post on servers or to redistribute to lists, requires prior specific permission and/or a fee. Request permissions from permissions@acm.org.

TEEM'20, October 21-23, 2020, Salamanca, Spain

(C) 2020 Association for Computing Machinery.

ACM ISBN 978-1-4503-8850-4/20/10 . \$ \$15.00

https://doi.org/10.1145/3434780.3436577

\section{ACM Reference Format:}

Maria Giulia Ballatore, Gavin Duffy, Sheryl Sorby, and Anita Tabacco. 2020. SAperI: approaching gender gap using Spatial Ability training week in high-school context. In Eighth International Conference on Technological Ecosystems for Enhancing Multiculturality (TEEM'20), October 21-23, 2020, Salamanca, Spain. ACM, New York, NY, USA, 7 pages. https://doi.org/10. $1145 / 3434780.3436577$

\section{INTRODUCTION}

The purpose of this paper is to describe the structure of an Italian experience of a summer school for girls designed to improve their spatial ability and prepare them for their future careers in a STEMM (Science, Technology, Engineering, Mathematics, and Medicine) field.

Historically, the term spatial ability (SA) has been used to describe a variety of relatively autonomous human intellectual competencies [11] related to the representation, transformation, generation, and recall of symbolic, nonlinguistic information [23, 25]. Different categories or factors of spatial ability have been identified over time $[3,5,23,25]$. This paper will employ the classification of these factors made by Linn and Petersen: spatial perception, mental rotation, and spatial visualization [23].

Different studies have proven the existence of a strong relation of spatial ability to mathematics and scientific thinking [8, 14, 28], performance on standardized tests (SATs) [6], and predictive validity of occupational aptitude tests [12]. In other words, those who are deemed to be well suited to STEMM careers having taken an occupational aptitude test tend to also score highly on tests of spatial ability. The association between spatial ability and science and engineering career preference was also revealed in a longitudinal study that tracked participants from high school through university and subsequent career path [43]. In particular, considering the survey by the U.S. Employment Service [40], engineering, science, drafting, and designing account for $85 \%$ of all jobs requiring a high level of SA.

This can be intuitively confirmed by the types of skill that STEMM careers require. For example, all engineers must be very quick at reading and interpreting graphs, solve complex part-whole relations by recognizing the interactions of the parts of a machine, and passing from a mathematical model to the real world. In 
medicine, a surgeon must develop cognitive images and a radiologist must be able to interpret an X-rays [19], often having to reorient their perspective if the image is mirrored or taken from a different orientation to the view provided. In a similar way, scientists need to apply these skills as well, for example, while they read the periodic table in which the scientific content is spatially organized, or while they sample in the labs using microscope observations, or by the use of map representations of natural phenomena [32].

The relation between SA and STEMM careers has been the subject of much research which confirm its predictive validity through longitudinal study that took into consideration students' behavior over a long period of time, from 20 to 50 years [43]. However, this does not imply that people with low SA should exclude STEMM as a future career, because numerous studies show that spatial skills can be learned [31, 36, 41].

SA is malleable, that is, it can be trained and improved at any age either directly or indirectly [38, 44]. Moreover, this spatial development seems to be durable, lasting for at least several months, interchangeable between SA factors, and transferable to other tasks and settings [38, 41]. For example, by training mental rotation one indirectly improves spatial perception as well [32]. Indeed, from a psychological point of view, due to the direct contribution of working memory executive functioning, the spatial ability categories tapped by the psychometric tests are correlated but separable [29]

Moreover, the increase of SA training can have a direct impact on educational outcomes, such as giving the right support to complete engineering degrees [22, 35, 36].

Robust gender differences are observed in SA, that is, males typically outperform females on certain tests, especially tests of mental rotation [42]. Linn and Petersen (1985) in their meta-analysis try to answer to the question "On which aspects of spatial ability are sex differences found?". It appears that an assortment of mechanisms favour the emergence of a sex difference, that is, environment and biological mechanisms. The magnitude of this difference varies among SA categories and it is detected across the life span. The largest sex differences are found on measures of mental rotation $[7,13,17,20,24,30,33,42]$, while smaller sex differences are found on measures of spatial perception [21,23].

A gender difference has also been observed in strategies used to solve problems $[10,25,30]$. Typically, men apply holistic strategies which seem to be very quick and accurate, instead, women prefer analytical strategies which penalizes them particularly if the tests are time limited [4, 15, 37]. The term 'holistic strategies' is used here to refer to the retrieval from memory of parallel processes that allow one to mentally rotate the whole figure until it coincides with the target [16]. In contrast, analytical strategies refer to verbal processes and manipulative solution, i.e. counting cubes [39].

Another element that needs to be considered while referring to sex differences is psychological stereotypes [1]. Indeed, females perceive SA tasks as masculine and are more intimidated by them than are males [27]. This apparently simple difference reflects a deeper approach to real-life problems in which males are usually more competitive than females and overestimate their abilities [26].

Intending to enhance SA, Sorby [35] has developed training for first-year engineering students. The course shows a positive boost both for males and for females not only in SA but also in the regular engineering curricula [35]. What is not yet clear is the impact this course can have on adolescent girls that are about to enter higher education. This paper attempts to show the structure and the results of "SAperI - Spatial Ability per l'Ingegneria" (in English: Knowledge - Spatial Ability for Engineering) an intense summer school in Italy for 17 years-old girls.

This paper begins by introducing the context of the Italian education system and the study itself and it will then go on to the details of the research questions. The fourth section describes the methodology used in the study. Section 5 analyses the results of the training week followed by discussion and general conclusions.

\section{CONTEXT}

In the Italian education system, children complete a first cycle of education, lasting 8 years (from 6-year-old to 14-year-old), followed by a second cycle of education, lasting five years (from 14-yearold to 19-year-old). The second cycle consists of upper secondary schools governed by the state and classified by the type of curricula they teach as Lycée (general schools), technical institutes, and vocational institutes. Ministry of Education establishes the basic curriculum for all upper secondary school and divides them into sub-tracks (i.e. Classical Lycée, Scientific Lycée, Mechanical technical institute, ICT technical institute, ...). Mathematics is a fundamental discipline common to all schools but there is a differentiation on the number of hours per week. Similarly, Science is divided into separate subjects (i.e., chemistry, physics, and biology) and not all science subjects are taught in every type of school each year. Although some universities foresee an admission test, every track allows access to any kind of university.

With regard to gender, women are more likely than men to choose social science and educational Lycée while men prefer technical school. In contrast, Scientific Lycée has homogeneous distribution with regard to gender.

A similar trend can be found in higher education as illustrated in Figure 1 where the data for academic year 2017/2018 are shown. This distribution is almost constant over time.

As shown in Figure 1, there is a very large gender gap in representation in Engineering education. As a profession, engineering is extremely important to society and it is important that women are represented equally in the engineering profession so that engineering solutions are not biased in favour of one group over another. Those qualities are useful in a society based more and more on team work, lifelong learning and context complexity [9]. Even if growing, the number of women engineers is still limited, possibly compounded by a widely held belief that engineering is a job just for men. It is necessary to increase the representation of women enrolled in Engineering at university level in order to overcome the image of the engineer as a predominantly male figure.

Politecnico di Torino (PoliTo) is a technical university with Engineering and Architectural courses located in the north of Italy. Thanks to different actions over the last number of years, PoliTo has made improvements in attracting female students. Despite these efforts, more remains to be done both for the student population and for high level academic positions. During the academic year 2017/18, 29\% of applicants (out of 8127 students) were female and, considering the enrolled students (4508), $24 \%$ of them were female. 


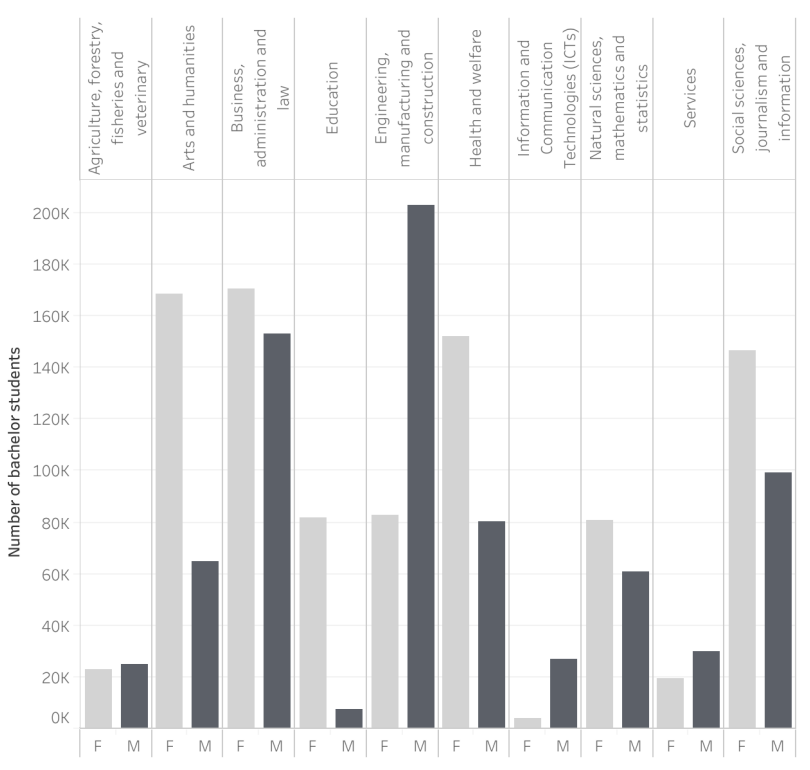

Figure 1: Distribution of bachelor students 2017/18 by gender following the ISCED classification (data source: MIUR open data [9])

In its Strategic Plan 2018-2024, Polito has included "Polito4impact", a set of specific objectives to raise the average percentage of female students enrolled in the first year of engineering programs to over $35 \%$ and to achieve full gender equality in some degree programs within the next 6 years [34].

To reach this goal, the following specific actions have been put in place:

- involvement of middle and high school female students and related mentoring in cooperation with other local bodies and companies concerned about the gender issue;

- development of specific incentives during both the preenrolment and enrolment phases.

Moreover, a dedicated team has been established, PoliWo PoliTo for Women, with a related project, "WeAreHere" (https: //weareherepolito.it/), which aims to raise awareness of the gender gap, make STEMM more attractive to women and provide support during the study and job placement. As part of this project the "SAperI" summer school for high-school girls was organized.

\section{RESEARCH QUESTIONS}

This study, therefore, set out to assess the effect of a training school dedicated to SA development on young girls. One purpose of this study was to assess the extent to which stereotype factors were influencing girls' interest in improving their spatial ability. Besides, this study was designed to investigate the effect of an intense spatial training course and the persistence of any spatial ability improvements over time.

To summarize, the research questions can be stated as:

- Are girls interested in improving their spatial ability?
- Is intense training of 5 days sufficient to effect significant improvement?

- If there was an improvement, was the improvement persistent over time?

\section{METHODOLOGY}

The SAperI summer school was part of a wider project which involved fourth-year high-school students, both male and female, in 2019. The project was divided into 3 steps: (a) preliminary evaluation, (b) summer school, (c) final evaluation. The preliminary evaluation, in May 2019, consisted of a computer-based series of tests related to the three categories of SA and was open to all the interested students regardless of gender. The second step, in June 2019 , was dedicated to females that took the preliminary evaluation and that were interested in improving their SA through a 5 day training week. At the end of the summer school a new section of the series of tests was performed. Then in September 2019, the final evaluation, which involved again all the students of phase (a), and consisted of a repeat of the same series of tests.

The series of test were computed-based and included:

- Revised Purdue Spatial Visualization Tests: Visualization of Rotations (Revised PSVT:R) - 30 items - 20 minutes [18]

- Modified Lappan Spatial Visualization Assessment (Lappan) - 10 item - 8 minutes [18]

- Santa Barbara Cross Section mental cutting test (SBCS) - 30 items - 15 minutes [2]

- Paper Folding component of the Differential Aptitude Test (DAT) - 10 item - 8 minutes [2]

This paper is focused on step (b) and will refer only to the participants directly involved in the summer school.

PoliTo has a long and established network of high schools, called "Progetto Orientamento", inside Piedmont and Valle d'Aosta regions for activities related to the attraction campaigns. In order to address the research questions, a general call was sent to all the Progetto Orientamento partners. 11 high schools answered with 172 students (95 females and 77 males). Of them, the participants interested to participate in a SA summer school were 46, but after the preliminary evaluation, only 37 accepted to attend. Due to personal reasons, 2 girls were absent to the final evaluation (step (c)), so 35 girls completed the entire project.

Students did not know the content of the series of tests, they were invited to participate to discover their SA level as an aptitude test useful as a trial for University incoming tests.

The summer school was scheduled for 5 mornings of 4 hours each (Monday to Friday) and 3 afternoons of 3 hours each (Tuesday to Thursday). In the morning section, 5 modules of the training course developed by Sorby [35] were used. The afternoon sections consisted of competitions in small groups about topics related to SA: Trail-O, Graphical Solving, and Origami and Touch sketch (see the program in Table 1). At the end of the summer school, they returned all the materials received and retook the series of tests from the preliminary evaluation phase. In addition, an anonymous satisfaction survey was sent to them by email. 
Table 1: Summer school week schedule

\begin{tabular}{|c|c|c|}
\hline & Morning & Afternoon \\
\hline June $17^{\text {th }} 2019$ & $\begin{array}{l}\text { Introduction and } \\
\text { Module A } \\
\text { (Isometric drawing } \\
\text { and coded plan) }\end{array}$ & Free \\
\hline June $18^{\text {th }} 2019$ & $\begin{array}{l}\text { Module B (Rotation } \\
\text { of objects about a } \\
\text { single axis) }\end{array}$ & Trail-O \\
\hline June $19^{\text {th }} 2019$ & $\begin{array}{l}\text { Module C } \\
\text { (Orthographic } \\
\text { drawings) }\end{array}$ & $\begin{array}{l}\text { Graphical problem } \\
\text { solving }\end{array}$ \\
\hline June $20^{\text {th }} 2019$ & $\begin{array}{l}\text { Module D } \\
\text { (Rotation of objects } \\
\text { about two or more } \\
\text { axes) }\end{array}$ & $\begin{array}{l}\text { Origami e Touch } \\
\text { Sketch }\end{array}$ \\
\hline June $21^{\text {st }} 2019$ & $\begin{array}{l}\text { Module E (Flat } \\
\text { patterns) and final } \\
\text { tests }\end{array}$ & Free \\
\hline
\end{tabular}

\subsection{Morning sections}

For the morning activities, each girl received a personal workbook, 10 snapcubes and a xyz axis made by K'Nex (Figure 2). For each module, there was a short introduction by a female facilitator, followed by some exercises at the blackboard using snapcubes to help the mental visualization process. Then, students explored in pairs the topic through some computer-based graphical exercises during which they could share solution approaches. Moreover, participants had to complete by themselves the workbook exercises with the assistance, if needed, of two facilitators, a man and a woman. At the end of the morning, the female facilitator showed the solutions and shared different solution strategies. The school materials (slides, computer-based exercises and workbook) were based on Sorby's course and therefore they were in English, while the mornings lectures were in Italian.

Note that intentionally no formal training was done on mental cutting. Thus, considering the chosen tests, the ability tested by SBCS were not part of the summer school content.

\subsection{Afternoon sections}

The afternoon activities were meant to be a "play and learn" challenge. Participants were divided into different groups or pairs each day trying to have a homogeneous distribution of the results of the preliminary tests among them. The groups were named after STEMM women role models (i.e., Emma Strada, Ipazia, Edith Clark, Annie Easley, Hedi Lammar, Samantha Cristoforetti, Maryam Mirzakhani, etc.), while the pairs were named after famous inventions created by women (i.e., circular saw, mechanical dishwasher, windscreen wipers, bra, disposable diapers, pedal bin, etc.).

The first activity was Trail-O, a discipline of Orienteering that does not involve a physical component and can be performed at a desk using a map and compass at observation points. The activities were organized in collaboration with a local association of Orienteering. First, they presented the basic concepts behind this sport

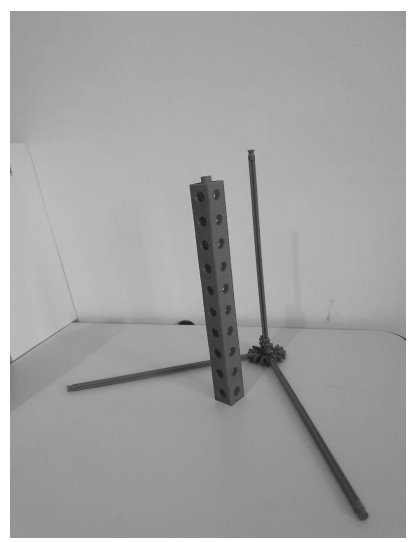

Figure 2: Materials available to each participant: 10 snapcubes and xyz K'Nex

and then they proposed 5 small game sections involving different aspects of Trail-O with increasing difficulty. At the end of the day, the solutions of each group were collected and secretly scored.

During the second afternoon participants completed activities related to graphical problem-solving. During the first half of the afternoon, they solved some guided exercises discovering their "favourite" solution strategy and exploring graphical solutions. Later they performed a group problem-solving competition with 10 problems of various difficulty with time bonuses and penalties.

On the last afternoon there was a lesson on technological origami applications with some short practice sections followed by the final phase of the competition. The challenge consisted of 3 tasks: (1) follow some instruction to build a complex origami, (2) reproduce a given origami, and (3) sketch the isometric and the orthographic drawing of 2 objects that could be touched but not seen: a soft shape and a complex snapcube construction. The two objects were placed inside a box with a small hand hole so they were not visible to the participants and could be touched and felt only.

As the groups and the pairs changed every day, each girl obtained a different score calculated from the sum of the 3 activities. At the end of the week only the first 3 participants were announced, and they received a prize.

\section{FINDINGS}

At the SAperI call, 172 students answered positively, although only 167 came to PoliTo for the preliminary evaluation. At the end of the series of tests, each student could see his/her personal score in each test. In general, males outperformed females in all four tests (Table 2).

The participants willing to take part at the summer school appeared to be a representative sample of the female experimental group. As the mean spatial ability score of the participants that actually took part at SAperI summer school is slightly higher than those who were willing to participate, it seems that those who opted not to take the course had slightly lower SA.

All 37 participants actively participated during the entire summer school. They all completed the workbook exercises and spent time sketching by hand. Comparing the results of the tests obtained at 
Table 2: Descriptive statistics of the preliminary evaluation considering the different populations (Males, Females, Females interested on the summer school, and Females that took part of the summer school)

\begin{tabular}{llllll}
\hline & $\mathrm{N}$ & Revised PSVT:R & Lappan & SBCS & DAT \\
\hline Males & 74 & $\mathrm{M}=19.15$ & $\mathrm{M}=5.73$ & $\mathrm{M}=19.47$ & $\mathrm{M}=7$ \\
& & $\mathrm{SD}=5.84$ & $\mathrm{SD}=2.46$ & $\mathrm{SD}=6.82$ & $\mathrm{SD}=2.55$ \\
Females & 93 & $\mathrm{M}=16.23$ & $\mathrm{M}=4.45$ & $\mathrm{M}=17.13$ & $\mathrm{M}=6.62$ \\
& & $\mathrm{SD}=4.78$ & $\mathrm{SD}=2.02$ & $\mathrm{SD}=7.72$ & $\mathrm{SD}=2.17$ \\
Females interested on & \multirow{2}{*}{46} & $\mathrm{M}=16.61$ & $\mathrm{M}=4.93$ & $\mathrm{M}=18.15$ & $\mathrm{M}=6.80$ \\
Summer school & & $\mathrm{SD}=5.32$ & $\mathrm{SD}=2.13$ & $\mathrm{SD}=7.13$ & $\mathrm{SD}=2.33$ \\
Female took part of & \multirow{2}{*}{37} & $\mathrm{M}=17.14$ & $\mathrm{M}=5.05$ & $\mathrm{M}=18.46$ & $\mathrm{M}=7.03$ \\
Summer school & & $\mathrm{SD}=5.37$ & $\mathrm{SD}=2.21$ & $\mathrm{SD}=7.00$ & $\mathrm{SD}=2.17$ \\
\hline
\end{tabular}

Table 3: Comparison between the results of tests related to step (a) and (b) of the 37 participants attending the SAperI summer school

\begin{tabular}{lllll}
\hline $\begin{array}{l}\text { N }\left\{{ }^{\circ}\right\} \text { of } \\
\text { participants } \\
\text { with: }\end{array}$ & $\begin{array}{l}\text { Revised } \\
\text { PSVT:R }\end{array}$ & Lappan & SBCS & DAT \\
\hline $\begin{array}{l}\text { Improved } \\
\text { score }\end{array}$ & 32 & 32 & 30 & 26 \\
Same score & 4 & 3 & 3 & 7 \\
Lower score & 1 & 2 & 4 & 4 \\
\hline
\end{tabular}

the end of the SAperI summer school with the preliminary one, the findings are interesting (Table 3). The majority of the participants improved or maintained their scores in all the tests apart from the DAT where $10 \%$ of participants recorded a lower score. One thing that needs to be considered while analysing this DAT abnormality is the fact that participants took the tests after an intense morning and they could have been tired. Moreover, the last module in the curriculum was about flat patterns and it seems they had not enough time to properly elaborate the content.

From these data, a further comparison has been made between the 3 series of tests (step (a), (b), and (c)). Figure 3 is a graphical interpretation of the results obtained by each girl, that is, the 3 scores are plotted in columns by using different symbols (back arrow refers to preliminary results, dot refers to summer school results, and forward arrow refers to the final results). The data of each test typology are ordered by the results of the preliminary series of tests. What stands out is that, generally speaking, the results achieved after the summer break keep improving or confirming the results obtained at the end of the summer school. Considering Revised PSVT:R and Lappan results, in the worst cases participants' results went back at the preliminary level. While participants with a preliminary high score in SBCS performed with an abnormal trend with final results lower than the previous one $(13 \%$ of the school attendants). Similarly, also in this case, the DAT test showed some anomaly.

These observations are confirmed by the descriptive statistics in Table 4 which refers to the 35 girls who took the all 3 steps series of tests.

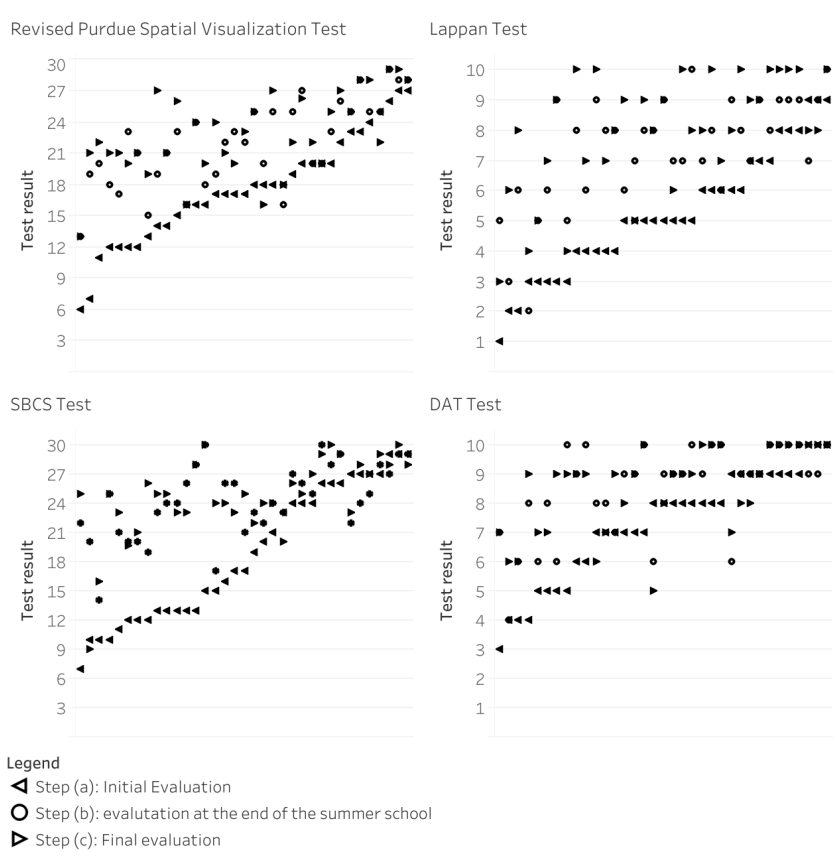

Figure 3: Graphical comparison between the results of the three series of tests (step (a), step (b), and step (c))

Another element that needs to be analysed to understand the impact of the SAperI summer school is the feedback survey. Using a 5-point Likert scale (1- strongly disagree, 2 - disagree, 3 -neutral, 4 - agree, 5 - strongly agree), participants were asked to judge the whole experience as well as the different activities (the morning lessons, the afternoon contents and the challenge). Of the study population, 28 participants (76\%) completed the survey.

The majority of those who responded felt that the summer school was an extremely positive experience (43\%) or a positive experience $(39 \%)$. They agree (43\%) and strongly agree $(32 \%)$ that the summer school met their expectations. When asked if they considered the week organized in a precise and efficient way, $61 \%$ of the respondents reported that it was extremely well organized (5 in Likert scale). Only $2(7 \%)$ indicated that they perceived the activities were not useful for the school goal and they perceived poor improvement 
Table 4: Descriptive statistics of the results achieved by the participants that complete the all SAperI project

\begin{tabular}{|c|c|c|c|c|}
\hline & $\begin{array}{l}\text { Revised } \\
\text { PSVT:R }\end{array}$ & Lappan & SBCS & DAT \\
\hline \multirow[t]{4}{*}{ Step (a) } & $\operatorname{Min}=6$ & $\operatorname{Min}=1$ & $\operatorname{Min}=7$ & $\operatorname{Min}=3$ \\
\hline & $\operatorname{Max}=27$ & $\operatorname{Max}=9$ & $\operatorname{Max}=29$ & $\operatorname{Max}=10$ \\
\hline & $M=17,49$ & $M=5,2$ & $M=18,77$ & $M=7,28$ \\
\hline & $\mathrm{SD}=5,22$ & $\mathrm{SD}=2,10$ & $\mathrm{SD}=6,91$ & $\mathrm{SD}=1,92$ \\
\hline \multirow[t]{4}{*}{ Step (b) } & $\operatorname{Min}=13$ & $\operatorname{Min}=2$ & $\operatorname{Min}=14$ & $\operatorname{Min}=4$ \\
\hline & $\mathrm{Max}=29$ & $\operatorname{Max}=10$ & $\operatorname{Max}=30$ & $\operatorname{Max}=10$ \\
\hline & $M=21,94$ & $M=7,34$ & $M=24,20$ & $M=8,51$ \\
\hline & $\mathrm{SD}=4,07$ & $\mathrm{SD}=1,85$ & $\mathrm{SD}=3,78$ & $\mathrm{SD}=1,58$ \\
\hline \multirow[t]{4}{*}{ Step (c) } & $\operatorname{Min}=13$ & $\operatorname{Min}=3$ & $\operatorname{Min}=9$ & $\operatorname{Min}=5$ \\
\hline & $\operatorname{Max}=29$ & $\operatorname{Max}=10$ & $\operatorname{Max}=30$ & $\operatorname{Max}=10$ \\
\hline & $M=22,77$ & $M=7,97$ & $M=24,69$ & $M=8,54$ \\
\hline & $\mathrm{SD}=3,94$ & $\mathrm{SD}=1,98$ & $\mathrm{SD}=4,21$ & $\mathrm{SD}=1,44$ \\
\hline
\end{tabular}

on SA. An interesting result is the one related to question about the opportunity to recommend this school, only one girl (3\%) would not recommend it, while 12 of them (43\%) would strongly do it, 11 would do it (40\%), and 4 would be neutral (14\%).

\section{CONCLUSIONS}

This project was undertaken to design an intense training school to develop SA and evaluate its effect on adolescent females. These experiments confirmed that, for this age group and gender, SA can be trained and that the improvement is maintained over time.

Referring to the research questions, girls' interest in improving their SA was not affected by their initial SA level. The participants at the summer school covered the entire range of scores. Although some of them found the content of the school hard, what stands out from the survey is that they like the approach used during the morning training sessions and perceived a personal improvement. The majority seem to perceive personal improvement regardless of test results. Moreover, they would recommend the school to other friends. The main drawback point raised by some participants in the open comments was the afternoon competition. They found it stressful in particular the problem-solving challenge that was time-limited. They suggested extending the peer to peer sections, now limited to the computer-based exercises, with dedicate hand drawing activities in pairs.

Considering the results achieved on the series of tests at the end of the summer school, the intense training seemed to positively improve their SA level. However, a limitation that needs to be taken into consideration is the fact that the tests were done right after the last training module. The participants only had a 15 minute break before starting the one hour testing session. It is quite possible that tiredness had a negative impact especially on the last test, the DAT. Indeed, in this case, some participants decreased their score.

The improvements were persistent overtime for mental rotation and spatial visualization tests, but for the mental cutting test, there were girls who decreased their score. This could be related to the fact that during the summer school there was no direct training on this spatial factor.
These findings suggest that in general intense training can be used to improve SA in adolescence girls obtaining significant improvements that persist over time.

Further work needs to be done to establish the relationship between the control group and the experimental group, especially in the series of tests after the summer break.

\section{ACKNOWLEDGMENTS}

The authors acknowledge the Politecnico di Torino for the financial and management support of the SAperI summer school. In particular, the authors are thankful to the Vice Rector for quality, welfare and equal opportunities, Claudia De Giorgi, to the Rector's advisor for gender equality and diversity, Arianna Montorsi, and to the Office of orientation, tutoring, counselling and disability services.

The authors would also like to show their gratitude to all the students who took part in the project.

\section{REFERENCES}

[1] Ballatore, M.G., Barman, L., de Borger, J., Ehlermann, J., Fryers, R., Kelly, K., Misiewicz, J., Naimi-Akbar, I. and Tabacco, A. 2019. Increasing gender diversity in STEM: A tool for raising awareness of the engineering profession. $A C M$ International Conference Proceeding Series (2019).

[2] Bennett, G. 1973. Differential aptitude tests: forms S and T.Psychological Corporation.

[3] Burton, L.J. and Fogarty, G.J. 2003. The factor structure of visual imagery and spatial abilities. Intelligence. 31, 3 (May 2003), 289-318. DOI:https://doi.org/10. 1016/S0160-2896(02)00139-3.

[4] Carr, M. and Davis, H. 2001. Gender Differences in Arithmetic Strategy Use: A Function of Skill and Preference. Contemporary Educational Psychology. 26, 3 (Jul. 2001), 330-347. DOI:https://doi.org/10.1006/ceps.2000.1059.

[5] Carroll, J.B. 1993. Human cognitive abilities: a survey of factor-analytic studies. Cambridge University Press.

[6] Casey, M.B., Nuttall, R., Pezaris, E. and Benbow, C.P. 1995. The influence of spatial ability on gender differences in mathematics college entrance test scores across diverse samples. Developmental Psychology. 31, 4 (1995), 697-705. DOI:https: //doi.org/10.1037/0012-1649.31.4.697.

[7] Coluccia, E. and Louse, G. 2004. Gender differences in spatial orientation: A review. Fournal of Environmental Psychology. 24, 3 (Sep. 2004), 329-340. DOI:https: //doi.org/10.1016/j.jenvp.2004.08.006.

[8] Delgado, A.R. and Prieto, G. 2004. Cognitive mediators and sex-related differences in mathematics. Intelligence. 32, 1 (Jan. 2004), 25-32. DOI:https://doi.org/10.1016/ S0160-2896(03)00061-8.

[9] Directorate General for Research and Innovation, E.C. 2018. She figures 2018. Publications Office of the European Union.

[10] Freedman, R.J. and Rovegno, L. 1981. Ocular dominance, cognitive strategy, and sex differences in spatial ability. Perceptual and motor skills. 52, 2 (Apr. 1981), 651-4. DOI:https://doi.org/10.2466/pms.1981.52.2.651.

[11] Gardner, H. 1993. Multiple intelligences: The theory inpractice. Basic Books.

[12] Ghiselli, E.E. 1973. The validity of aptitude tests in personnel selection. Personnel Psychology. 26, 4 (Dec. 1973), 461-477. DOI:https://doi.org/10.1111/j.1744-6570. 1973.tb01150.x

[13] Halpern, D.F., Benbow, C.P., Geary, D.C., Gur, R.C., Hyde, J.S. and Gernsbacher, M.A. 2007. The Science of Sex Differences in Science and Mathematics. Psychological Science in the Public Interest. 8, 1 (Aug. 2007), 1-51. DOI:https: //doi.org/10.1111/j.1529-1006.2007.00032.x.

[14] Hawes, Z. and Ansari, D. 2020. What explains the relationship between spatial and mathematical skills? A review of evidence from brain and behavior. Psychonomic Bulletin and Review. Springer.

[15] Hugdahl, K., Thomsen, T. and Ersland, L. 2006. Sex differences in visuo-spatial processing: An fMRI study of mental rotation. Neuropsychologia. 44, 9 (Jan. 2006), 1575-1583. DOI:https://doi.org/10.1016/j.neuropsychologia.2006.01.026.

[16] Just, M.A. and Carpenter, P.A. 1985. Cognitive coordinate systems: Accounts of mental rotation and individual differences in spatial ability. Psychological Review. 92, 2 (1985), 137-172. DOI:https://doi.org/10.1037/0033-295X.92.2.137.

[17] Kimura, D. 1999. Sex and cognition. MIT Press.

[18] Lappan, G. 1981. Middle grades mathematics project: spatial visualization test. MSU Mathematics Dept., Middle Grades Mathematics Project.

[19] Levine, S.C., Huttenlocher, J., Taylor, A. and Langrock, A. 1999. Early sex differences in spatial skill. Developmental Psychology. 35, 4 (1999), 940-949. DOI:https://doi.org/10.1037/0012-1649.35.4.940. 
[20] Levine, S.C., Vasilyeva, M., Lourenco, S.F., Newcombe, N.S. and Huttenlocher, J. 2005. Socioeconomic Status Modifies the Sex Difference in Spatial Skill. Psychological Science. 16, 11 (Nov. 2005), 841-845. DOI:https://doi.org/10.1111/j.14679280.2005.01623.x

[21] Liben, L.S. and Colbeck, S.L. 1980. Sex differences in performance on Piagetian spatial tasks: Differences in competence or performance? Child Development. 51, (1980), 594-597.

[22] Lin, H. 2016. Influence of design training and spatial solution strategies on spatial ability performance. International fournal of Technology and Design Education. 26, 1 (Feb. 2016), 123-131. DOI:https://doi.org/10.1007/s10798-015-9302-7.

[23] Linn, M.C. and Petersen, A.C. 1985. Emergence and Characterization of Sex Differences in Spatial Ability: A Meta-Analysis. Child Development. 56, 6 (Dec. 1985), 1479. DOI:https://doi.org/10.2307/1130467.

[24] Masters, M.S. and Sanders, B. 1993. Is the gender difference in mental rotation disappearing? Behavior Genetics. 23, 4 (Jul. 1993), 337-341. DOI:https://doi.org/ 10.1007/BF01067434.

[25] McGee, M.G. 1979. Human spatial abilities: Psychometric studies and environmental, genetic, hormonal, and neurological influences. Psychological Bulletin. 86, 5 (Sep. 1979), 889-918. DOI:https://doi.org/10.1037/0033-2909.86.5.889.

[26] Mercuri, G. 2019. La sindrome di Hermione: una spiegazione sul perché le ragazze vincono a scuola e perdono al lavoro. Corriere della Sera. (2019).

[27] Meyer, M. and Koehler, M.S. 1990. Internal influences on gender differences in mathematics. Mathematics and Gender. \& G.C.L. (Eds.) E. Fennema, ed. Teachers College Press. 60-95.

[28] Mix, K.S. and Cheng, Y.L. 2012. The Relation Between Space and Math. Developmental and Educational Implications. Advances in Child Development and Behavior. Academic Press Inc. 197-243.

[29] Miyake, A., Friedman, N.P., Rettinger, D.A., Shah, P. and Hegarty, M. 2001. How are visuospatial working memory, executive functioning, and spatial abilities related? A latent-variable analysis. fournal of Experimental Psychology: General. 130, 4 (2001), 621-640. DOI:https://doi.org/10.1037/0096-3445.130.4.621.

[30] Moè, A., Meneghetti, C. and Cadinu, M. 2009. Women and mental rotation: Incremental theory and spatial strategy use enhance performance. Personality and Individual Differences. 46, 2 (Jan. 2009), 187-191. DOI:https://doi.org/10.1016/ j.paid.2008.09.030

[31] Newcombe, N. 2010. Picture This: Increasing Math and Science Learning by Improving Spatial Thinking. American Educator. (2010), 29-43.
[32] Newcombe, N. 2013. Seeing Relationships: Using Spatial Thinking to Teach Science. American Educator. 37, 1 (2013), 26-40.

[33] Nordvik, H. and Amponsah, B. 1998. Gender Differences in Spatial Abilities and Spatial Activity Among University Students in an Egalitarian Educational System. Sex Roles. 38, 11/12 (1998), 1009-1023. DOI:https://doi.org/10.1023/A: 1018878610405.

[34] Politecnico di Torino 2018. PIANO STRATEGICO 2018 / 2024.

[35] Sorby, S. 2005. Assessment of a "New and Improved" Course for the Development of 3-D Spatial Skills" . Engineering Design Graphics fournal. 69, 3 (2005), 6-13.

[36] Sorby, S., Veurink, N. and Streiner, S. 2018. Does spatial skills instruction improve STEM outcomes? The answer is 'yes.' Learning and Individual Differences. 67, (Oct. 2018), 209-222. DOI:https://doi.org/10.1016/j.lindif.2018.09.001.

[37] Tapley, S.M. and Bryden, M.P. 1977. An investigation of sex differences in spatial ability: Mental rotation of three-dimensional objects. Canadian fournal of Psychology/Revue canadienne de psychologie. 31, 3 (1977), 122-130. DOI:https: //doi.org/10.1037/h0081655.

[38] Terlecki, M.S., Newcombe, N.S. and Little, M. 2008. Durable and generalized effects of spatial experience on mental rotation: gender differences in growth patterns. Applied Cognitive Psychology. 22, 7 (Nov. 2008), 996-1013. DOI:https: //doi.org/10.1002/acp.1420.

[39] Tzuriel, D. and Egozi, G. 2010. Gender Differences in Spatial Ability of Young Children: The Effects of Training and Processing Strategies. Child Development. 81, 5 (Sep. 2010), 1417-1430. DOI:https://doi.org/10.1111/j.1467-8624.2010.01482.x.

[40] U.S. Employment Service 1957. Estimates of worker trait requirements for 4,000 jobs. U.S. Government Printing Office.

[41] Uttal, D.H., Meadow, N.G., Tipton, E., Hand, L.L., Alden, A.R., Warren, C. and Newcombe, N.S. 2013. The malleability of spatial skills: A meta-analysis of training studies. Psychological Bulletin. 139, 2 (Mar. 2013), 352-402. DOI:https: //doi.org/10.1037/a0028446.

[42] Voyer, D., Voyer, S. and Bryden, M.P. 1995. Magnitude of sex differences in spatial abilities: A meta-analysis and consideration of critical variables. Psychological Bulletin. 117, 2 (1995), 250-270. DOI:https://doi.org/10.1037/0033-2909.117.2.250.

[43] Wai, J., Lubinski, D. and Benbow, C.P. 2009. Spatial ability for STEM domains: Aligning over 50 years of cumulative psychological knowledge solidifies its importance. Journal of Educational Psychology. 101, 4 (Nov. 2009), 817-835. DOI:https://doi.org/10.1037/a0016127.

[44] Willingham, D. 2009. Can We Make School More Enjoyable and Effective for "Slow" Students Too? American Educator. (2009), 10-11. 